\title{
AVIAN EXOCRINE SECRETIONS. I. CHEMICAL CHARACTERIZATION OF THE VOLATILE FRACTION OF THE UROPYGIAL SECRETION OF THE GREEN WOODHOOPOE, Phoeniculus purpureus
}

\author{
B. V. BURGER, B. REITER \& O. BORZYK. \\ Laboratory for Ecological Chemistry University of Stellenbosch, Private Bag X1, Matieland, 7602, South Africa. \\ M. A. DU PLESSIS \\ Percy FitzPatrick Institute, University of Cape Town, Rondebosch, 7701, South Africa.
}

\begin{abstract}
Using gas chromatography-mass spectrometry in conjunction with auxiliary techniques such as solid phase microextraction and determination of double bond positions by means of dimethyl disulfide derivatization, 45 constituents of the uropygial secretion of the green woodhoopoe, Phoeniculus purpureus, have been identified. The majority of these constituents are long-chain branched and unbranched alkanes, and (Z)-alkenes such as (Z)-9tricosene, and a number of unidentified wax esters. The more volatile fraction of the secretion contained shortchain fatty acids, aldehydes, aliphatic and heterocyclic aromatic amines, ketones, and dimethyl sulfides. This group of volatile compounds is responsible for the obnoxious odor of the secretion and also for its defensive action against predators.
\end{abstract}

Key Words: Phoeniculus purpureus, avian semiochemicals, defensive secretion, uropygial secretion.

\section{INTRODUCTION}

The uropygial gland of most birds produces a variety of hydrocarbons, lipids, waxes, fatty acids, alcohols, and other organic compounds (Jacob and Ziswiler, 1982). These have two widely recognized functions, viz. they are considered essential for the maintenance of good plumage condition, and may be used for fungicidal, bactericidal, or other hygienic purposes. Green woodhoopoes (also known as red-billed woodhoopoes), Phoeniculus purpureus, are group-territorial birds that live in groups comprising between 2 and 12 individuals (Ligon and Ligon, 1978). They are obligate cavity roosters and multiple individuals-usually all group members-will enter either a natural or bird-excavated cavity each night (Ligon and Ligon, 1978; du Plessis, 1989, 1992).

Individuals enter the roost cavities shortly after sunset and exit the following morning soon after sunrise. During the period that the birds are inside the roost, they apparently are vulnerable to a range of vertebrate predators, including snakes, genets, and rats (Ligon and Ligon, 1978). When disturbed while roosting, woodhoopoes immediately face away from the threat hence presenting their uropygial glands in the direction of the threat. Typically, a drop of brown, highly pungent secretion is then formed at the tip of the papilla to the uropygial gland, and kept in place by a few tuft-like feathers. This response pattern has led some observers to believe that the secretion serves an antipredatory role (Dallas, 1867, in Elder, 1954; Ligon and Ligon, 1978; du Plessis andWilliams, 1994).

The secretion has a persistent smell and frequently remains detectable for several hours on the hands of researchers who have handled them. Woodhoopoes also rank very low in terms of their taste to the human palate (Cott, 1945, 1946). The aim of this study was to determine the chemical composition of the volatile fraction of the uropygial secretion of the green woodhoopoe, excluding the wax esters, in order to identify the volatile constituents of the secretion for evaluation of their defensive properties against predators.

\section{METHODS AND MATERIALS}

\section{General}

All Pyrex glassware used in the handling of biological material and extracts, as well as in the preparation of reference compounds, was heated to $500^{\circ} \mathrm{C}$ in an annealing oven to remove any traces of organic material. 
Dichloromethane (Merck, Residue Analysis Grade) was analyzed gas chromatographically and found to be pure enough for extraction purposes when used in small quantities. This solvent was used to clean syringes, stainlesssteel needles, etc.

\section{Secretion Collection and Sample Preparation}

Uropygial gland secretion was collected either by wiping the exudates off the ring of fine bristles around the uropygial gland with pre-extracted surgical gauze squares, or by collecting the pure secretion in glass capillaries. In some instances, when the voluntary drop of secretion had been lost during capture, gentle finger pressure was applied to the base of the gland. This almost always resulted in the production of a further one to three drops of secretion. The volatile organic material was extracted from the secretion collected on gauze by extraction with dichloromethane (Reiter et al., 2003).

To collect the secretion in a capillary tube, the suspended drop of the secretion at the end of the papilla was touched with the tip of a capillary $(0.5 \mathrm{mmi}$.d.), which had been scored at a point about $10 \mathrm{mmfrom}$ its tip. Capillary forces caused the secretion tomove into the capillary. The end of the capillary containing the secretion was inserted into the mouth of a small vial and broken off at the scored position. The back end of the capillary, which served as a handle during the collection process, was discarded and the vial was sealed with a PTFEfaced septum. The collected secretion normally flowed out of the capillary and covered the bottom of the vial, and was sampled with solid phase microextraction (SPME) or was extracted with $100 \mu \mathrm{l}$ of dichloromethane.

Extracts could mostly be used without evaporation of the solvent. When more concentrated solutions were required, the solvent was removed with a slow stream of purified (activated charcoal) nitrogen.

\section{Analytical Methods.}

Gas chromatographic (GC) analyses were carried out with CarloErba 4200 and 5300 gas chromatographs equipped with flame-ionization detectors and Grob split/splitless injectors. Glass capillary columns were manufactured by the Laboratory for Ecological Chemistry and were coated with $0.25 \mu \mathrm{m}$ of the apolar stationary phase PS-089 (DB-5 equivalent) or with $0.375 \mu \mathrm{m}$ of OV-1701. Hydrogen was used as carrier gas at a linear velocity of $50.0 \mathrm{~cm} / \mathrm{sec}$ at $40{ }^{\circ} \mathrm{C}$. The flame-ionization detector was operated at $280^{\circ} \mathrm{C}$, and the injector was normally used at $220^{\circ} \mathrm{C}$. For qualitative work, samples of secretion extracts were injected in the split mode, the volatiles entering the column were cold trapped at ca. $30{ }^{\circ} \mathrm{C}$, and subsequently analyzed using a temperature program of $4{ }^{\circ} \mathrm{C} / \mathrm{min}$ from 40 to $280 \circ \mathrm{C}$ (hold).

Quantitative analyses were done with on-column introduction of aliquots of the extracts and the external standards, butyl ethyl ether and 1-icosene. A solventless sample introduction probe (Burger et al., 1990a) was used for sample introduction in GC and GC-MS analyses, and headspace analyses were done by SPME (Zhang and Pawliszyn, 1993) using a 100- $\mu$ m polydimethylsiloxane fiber. Headspace sampling times from $7 \mathrm{hr}$ at $22{ }^{\circ} \mathrm{C}$ to $72 \mathrm{hr}$ at $40 \circ \mathrm{C}$ were employed. Low-resolution electron impact mass spectra (EI-MS) were obtained at $70 \mathrm{eV}$ on a Carlo Erba QMD 1000 GC-MS instrument using the above columns and conditions. The injector temperature was set at $220^{\circ} \mathrm{C}$, the interface temperature at $250^{\circ} \mathrm{C}$, and the ion source temperature at $180^{\circ} \mathrm{C}$. A scan rate of $0.9 \mathrm{sec} / \mathrm{scan}$ with an interval of $0.1 \mathrm{sec}$ between scans was employed. Helium was used as carrier gas at a linear velocity of 28.6 $\mathrm{cm} / \mathrm{sec}$ at $40^{\circ} \mathrm{C}$.

${ }^{1} \mathrm{H}$ and ${ }^{13} \mathrm{C}$ NMR spectra of the total secretion and synthesized reference compounds were obtained on a Varian VXR-300 spectrometer at 299.9 $\mathrm{MHz}$ and $75.42 \mathrm{MHz}$, respectively.

\section{Determination of Double Bond Positions of Constituents.}

Dimethyl disulphide (DMDS) derivatives of the unsaturated constituents of the secretion were prepared according to Buser et al. (1983). An aliquot $(10 \mu \mathrm{l})$ of a dichloromethane extract of the uropygial secretion was concentrated in a 1-ml Reacti-Vial using a slow stream of purified nitrogen. The residual material was dissolved in hexane (50 $\mu \mathrm{l})$ and treated with $5 \mu \mathrm{l}$ of iodine solution $(60 \mathrm{mg} / \mathrm{ml}$ in diethyl ether) and dimethyl disulfide (50 $\mu \mathrm{l}$ ). The Reacti-Vial was sealed using a PTFE-faced rubber septum, and the reaction mixture was warmed for $15 \mathrm{hr}$ at $400^{\circ} \mathrm{C}$ in the oven of a gas chromatograph, after which the reaction was quenched with an aqueous solution of sodium thiosulfate (5\%). The organic and aqueous layers were separated by centrifuging for a few min at $2000 \mathrm{rpm}$, and the organic layer was transferred to a clean Reacti-Vial.

The solution was concentrated to ca. $5 \mu \mathrm{l}$ for GC-MS analysis. Reference Compounds. Compounds required for comparison with constituents of the uropygial secretion that were not commercially available were synthesized. (Z)-7-Henicosene was synthesized from 1-octyne and 1-bromotridecane (Ziegenbein, 1969), followed by catalytic 
hydrogenation of the resulting alkyne with Lindlar catalyst to yield the corresponding olefin. This procedure was also used for the synthesis of all the other alkenes used for retention time comparison with the natural compounds.

\section{RESULTS AND DISCUSSION}

Employing collection of the secretion in a capillary, about $5 \mathrm{mg}$ of the secretion could be collected from birds that had not lost any of the secretion during capture or handling. The secretion consisted largely of water and evaporation of the volatile material left only a foul smelling yellow stain on a glass surface. A typical total ion chromatogram obtained by GC-MS analysis of an extract of the secretion of an adult male is shown in Figure 1. Tentative identifications of the volatile organic constituents of the secretion were based on comparison of their mass spectra with those in the available NBS and Wiley mass spectra libraries. The compounds identified are listed in Table 1 together with information on the analytical techniques employed in their identification and some quantitative data on the major constituents present in the secretion in quantities higher than $0.1 \mu \mathrm{g} / \mathrm{animal}$.

Because the more volatile short-chain constituents of the secretion have characteristic mass spectra, their identificationwas simple. However, a large proportion of the constituents of the secretion were relatively large saturated and monounsaturated hydrocarbons. Of these, the unbranched isomers were identified by their distinctive MS fragmentation patterns and by co-elution with synthetic reference compounds. In the case of the methyl-branched components, the characteristic ions formed by fragmentation at branch points provided positive identification. The positions of the double bonds in the monounsaturated hydrocarbons were determined by GCMS analysis of an extract of the secretion that had been subjected to dimethyl disulfide derivatization (Buser et al., 1983). The characteristic fragments of the resulting bis(methylthioethers) are derived by the cleavage through the position of the (former) double bond of the alkene, the ion of higher mass having a higher intensity than the lower mass ion in all cases (Francis and Veland, 1981).

Another prominent diagnostic ion in the spectra of these derivatives is the (M-47) ion, formed by loss of a methylthio radical from the molecular ion. The configurations of the double bonds of the major unsaturated constituents of the secretion were established by NMR spectrometry. It is known that the allylic methylene carbon atoms resonate at $\delta \mathrm{ca} .27$ and at $\delta \mathrm{ca} .33$ in the ${ }^{13} \mathrm{CNMR}$ spectra of long-chain unbranched Z- and E-olefins, respectively (Wenkert et al., 1976; Breitmaier et al., 1979). The presence of a resonance at $\delta 27.9$ in the ${ }^{13} \mathrm{C}-\mathrm{NMR}$ spectrum of the secretion and the absence of a signal at about $\delta 33$ was therefore construed as evidence that the major unsaturated constituents of the secretion possessed $Z$ configuration. This was confirmed by the typical vicinal coupling constants of (Z)-olefins of $11.2 \mathrm{~Hz}$ (Hesse et al., 1987) observed in the $1 \mathrm{H}$-NMR-spectrum of the secretion.

The $(E)$ - and (Z)-isomers of the olefins present in the secretion were separable on the capillary columns used in the study and the configuration of the double bonds in these alkenes was confirmed by GC co-elution of a number of synthetic standards with some of the olefins in the secretion. GC-MS analyses of extracts of the secretion gave total ion chromatograms showing many constituents with retention times between 75 and 120 min (Figure 1). These compounds were found to be wax esters, which are likely to waterproof the feathers during preening. Most birds regularly rub their bills over the uropygial gland while grooming their feathers (Jacob and Ziswiler, 1982). It was relatively easy to derive the carbon numbers of the fatty acid and alcohol moieties of these esters from their mass spectra, which contained, inter alia, weak molecular ions. However, reference compounds synthesized from unbranched starting materials eluted with longer retention times than the natural compounds.

The natural substances therefore have to be branched isomers, which have not yet been identified. However, it is possible that branching of the type present in some of the volatile constituents of the secretion could also be present in these wax esters. Because of their low volatility, these compounds did not appear in total ion traces of SPME extracts from the headspace of the secretion, even when sampling was continued for up to $72 \mathrm{hr}$. The more volatile compounds, on the other hand, were present in higher relative amounts when headspace samples were analyzed. In general, only minor quantitative differences were observed between the secretions collected from different males and females. No consistent variation could be found between ranking and sex of the birds.

However, the secretion of one adult female was found to have a large preponderance of the various isomers of the fatty acids up to pentanoic acid. It is, therefore, possible that other, at this stage unknown, factors could have an influence on the quantitative composition of the secretion. The short-chain fatty acids, aldehydes, trimethylamine, indole, and dimethyl disulfide are responsible for the pungently unpleasant smell of the secretion. The occurrence of several volatile compounds, a wide variety of hydrocarbons, in particular monounsaturated olefins such as (Z)-9tricosene and (Z)-9-henicosene, as well as heavy wax esters, gives the impression that the uropygial secretion of the green woodhoopoe may function as more than a water proofing component for feathers. 
In insect and mammalian exocrine secretions, the active principles are often produced as mixtures with proteinaceous or non-volatile lipids that act as controlled release materials (Burger et al., 1990b, 1997). For example, nonvolatile lipids have been found in the uropygial secretion of grebes (Jacob, 1978). It is possible that the lipid constituents of the uropygial secretion could fulfill a similar function in the green woodhoopoe. However, it is doubtful that this is the primary function of the lipid constituents of the woodhoopoe's secretion, because this secretion contains too little material to be of much use as a controlled release carrier. The secretions of other animals using this dissemination mechanism contain a much larger proportion of either proteinaceous or lipid material.

The role of the uropygial material as a defensive secretion was recently confirmed in field tests. A formulation of a selection of the volatile representatives of each of the different compound classes in the secretion was found to be effective against feline predators and lizards (du Plessis et al., unpublished results). The full synthetic secretion was also tested against pathogenic and parasitic bacterial species identified from nest sites of birds and was found to be effective against several of these species, including Bacillus licheniformis, which degrades feathers (Burtt, 1999). This bacterium could be potentially lethal due to loss of insulation and impairment of the flight ability of birds. $B$. licheniformis showed a higher susceptibility to the synthetic secretion than any of the other pathogenic bacteria tested.

The uropygial secretion of the woodhoopoe, therefore, not only protects and waterproofs feathers but may also inhibit the growth of feather degrading bacteria.

\section{Acknowledgments}

Support of research reported in this paper by the University of Stellenbosch and the Foundation for Research Development, Pretoria, is gratefully acknowledged. The research was also supported by a Fyodor Lynen Postdoctoral Fellowship from the Alexander von Humboldt Foundation to O.B., a postdoctoral Fellowship from the Austrian Science Fund to B.R., and a grant from the Open Programme of the National Research Foundation, Pretoria, to M. du P. 
Figures

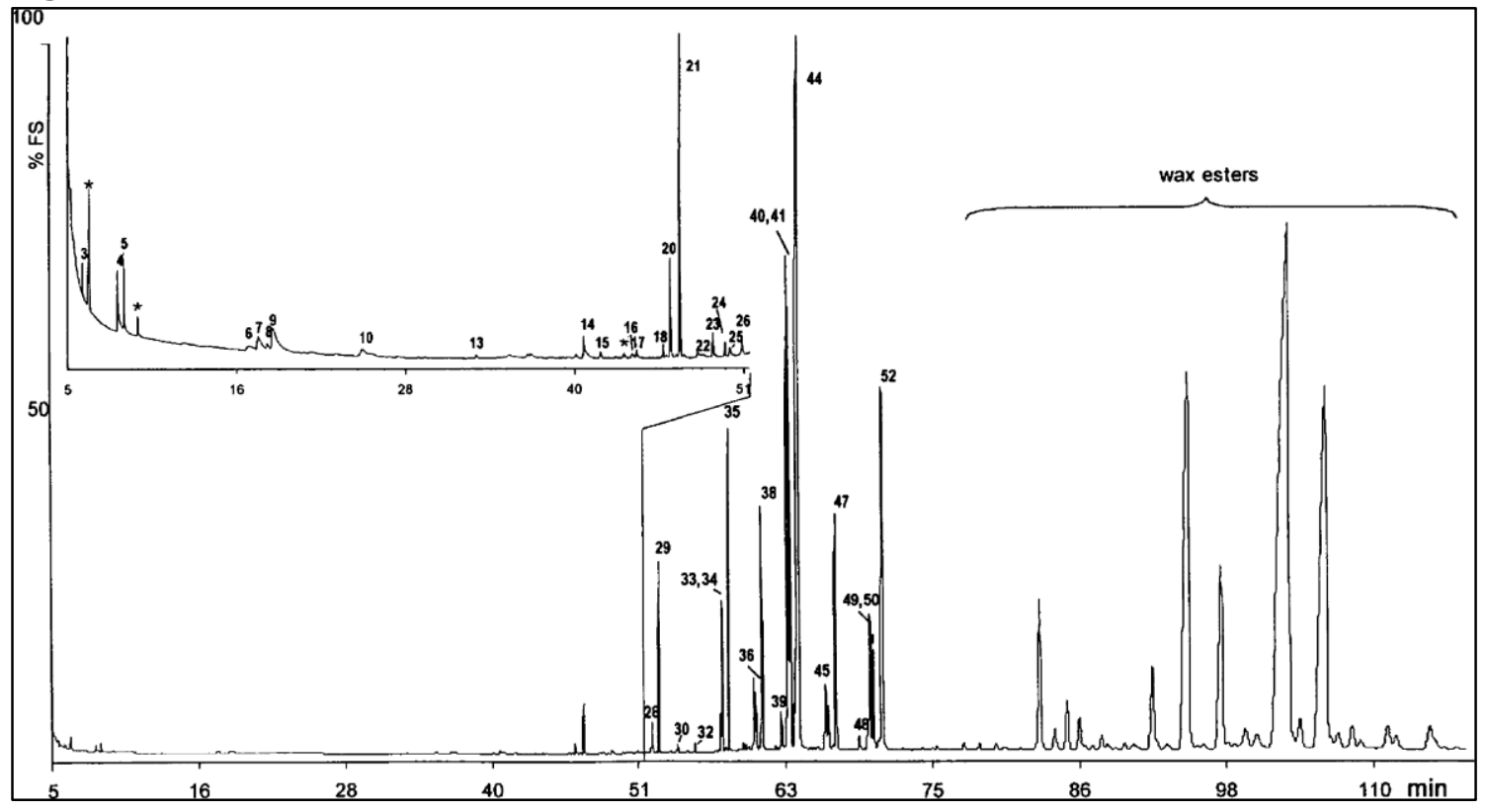

FIG. 1. Total ion chromatogram (TIC) of an extract of the uropygial secretion of the green woodhoopoe Phoeniculus purpureus. Gas chromatographic conditions: $40 \mathrm{~m} \times 0.3 \mathrm{~mm}$ ID glass column coated with PS-089 at a film thickness of $0.25 \mu \mathrm{m}$ and programed at $2{ }^{\circ} \mathrm{C}$ from $40 \circ$ to $250^{\circ} \mathrm{C}$ (hold); injector temperature $220{ }^{\circ} \mathrm{C}$. 
Tables

Table 1

COMPOUNDS IDENTIFIED IN THE UROPYGIAL SECRETION OF GREEN WOODHOOPOE

No. in Fig. 1 Compound Identification $\mu \mathrm{g} /$ animal $^{a}$

\begin{tabular}{|c|c|c|c|}
\hline 1 & Trimethylamine & $a, b$ & C \\
\hline 2 & Propanoic acid & $a, b$ & C \\
\hline 3 & 3-Methylbutanal & $a, b$ & 0.9 \\
\hline 4 & 3-Methylbutan-1-ol & $a, b$ & 3.0 \\
\hline 5 & Dimethyl disulfide & $a, b$ & 3.7 \\
\hline 6 & 4-Methylpentanoic acid & $a, b$ & 0.4 \\
\hline 7 & Benzaldehyde & $a, b$ & 2.0 \\
\hline 8 & Dimethyl trisulfide & $a, b$ & 0.1 \\
\hline 9 & Phenol & $a, b$ & 1.4 \\
\hline 10 & 2-Phenylethanol & $a, b$ & \\
\hline 11 & 2-Phenylethyl acetate & $a, b$ & \\
\hline 12 & Indole & $a, b$ & \\
\hline 13 & Tridecane & $a, b$ & \\
\hline 14 & Pentadecane & $a, b$ & \\
\hline 15 & Unidentified & & \\
\hline 16 & Hexadecane & $a, b$ & \\
\hline 17 & Unidentified & & \\
\hline 18 & 2-Methylhexadecane & $\mathrm{a}$ & 0.5 \\
\hline 19 & (Z)-Heptadec-7-ene & $a, e$ & \\
\hline 20 & (Z)-Heptadec-9-ene & $a, e$ & 3.4 \\
\hline 21 & Heptadecane & $a, b$ & 12.5 \\
\hline 22 & 13-Methyltetradecan-1- & $a, d$ & 0.5 \\
\hline 23 & 3-Methylheptadecane & $a$ & 0.9 \\
\hline 24 & Octadecane & $a, b$ & 0.7 \\
\hline 25 & Hexadecanal & $a, b$ & 0.5 \\
\hline 26 & 14-Methylpentadecan- & $a, b$ & 2.1 \\
\hline 27 & (Z)-Nonadec-7-ene & $a, e$ & 2.4 \\
\hline 28 & (Z)-Nonadec-9-ene & $a, e$ & 9.4 \\
\hline 29 & Nonadecane & $a, b$ & 64.7 \\
\hline 30 & 5-Methylnonadecane & $a$ & 6.5 \\
\hline 31 & (Z)-Icos-9-ene & $a, e$ & 1.4 \\
\hline 32 & Icosane & $a, b$ & 3.7 \\
\hline 33 & (Z)-Henicos-7-ene & $a, b, e$ & 16.0 \\
\hline 34 & (Z)-Henicos-9-ene & $a, b, e$ & 65.6 \\
\hline 35 & Henicosane & $a, b$ & 204 \\
\hline 36 & (Z)-Docos-7-ene & $a, e$ & 33.8 \\
\hline 37 & (Z)-Docos-9-ene & $a, e$ & 26.1 \\
\hline 38 & Docosane & $a, b$ & 143.8 \\
\hline 39 & Unidentified $\mathrm{C}_{23} \mathrm{H} 44$ & $a$ & 22.4 \\
\hline 40 & Unidentified $\mathrm{C}_{23} \mathrm{H}_{44}$ & $a$ & 15.2 \\
\hline 41 & (Z)-Tricos-7-ene & $a, e$ & 422 \\
\hline 42 & (Z)-Tricos-9-ene & $a, b, e$ & 306 \\
\hline 43 & Unidentified tricosene & a & 12.6 \\
\hline 44 & Tricosane & $a, b$ & 2570 \\
\hline 45 & (Z)-Tetracos-7-ene & $a, e$ & 86.7 \\
\hline 46 & (Z)-Tetracos-9-ene & $a, e$ & 1.1 \\
\hline 47 & Tetracosane & $a, b$ & 211 \\
\hline 48 & Unidentified $\mathrm{C}_{25} \mathrm{H}_{48}$ & $a$ & 13.1 \\
\hline 49 & Unidentified $\mathrm{C}_{25} \mathrm{H}_{48}$ & $a$ & 20.1 \\
\hline 50 & (Z)-Pentacos-7-ene & $a, e$ & 120 \\
\hline 51 & (Z)-Pentacos-7-ene & $a, e$ & 85.9 \\
\hline 52 & Pentacosane & $a, b$ & 575 \\
\hline
\end{tabular}

a Quantities lower than $0.1 \mu \mathrm{g}$ are not given. a, GC-MS analysis; b, retention time comparison with standard compounds (purchased or synthesized); c, observed in SPME analysis only; d, GC-MS analysis, retention time increment comparison; e, DMDS-derivatization 


\section{REFERENCES}

1. BREITMAIER, E., HAAS, G., and VOELTER, W. 1979. Compounds 36-105, Atlas of Carbon-13 NMR Data, Vol. 1 , Heyden, London.

2. BURGER, B.V.,MUNRO, Z., andBRANDT,W. F. 1990b. Pheromones of the Scarabaeinae II. Composition of the pheromone disseminating carrier material secreted by male dung beetles of the genus Kheper. $Z$. Naturforsch. 45c:863-872.

3. BURGER, B. V., MUNRO, Z., SMIT, D., SCHMIDT, U., WU, C.-L., and TIEN, F.-C. 1990a. Sample introduction in gas chromatography: Simple method for the solventless introduction of crude samples of biological origin. J. Chromatogr. 518:207-214.

4. BURGER, B. V., YANG, T.-P., LE ROUX, M., BRANDT, W. F., Cox, A. J., and HART P. F. 1997. Mammalian exocrine secretions $\mathrm{XI}$. Constituents of the preorbital secretion of klipspringer, Oreotragus oreotragus. J. Chem. Ecol. 23:2383-2400.

5. BURTT, E. H. 1999. Think small. Auk 116:878-881.

6. BUSER, H.-R., ARN, H., GUERIN, P., and RAUSCHER, S. 1983. Determination of double bond position in monounsaturated acetates by mass spectrometry of dimethyl disulfide adducts. Anal. Chem. 55:818-822.

7. COTT, H. B. 1945. The edibility of birds. Nature 156:736-737.

8. COTT, H. B. 1946. The edibility of birds. Proc. Zool. Soc. Lond. 116:371-524.

9. DU PLESSIS, M. A. 1989. The influence of roost-cavity availability on flock size in the red-billed woodhoopoe Phoeniculus purpureus. Ostrich Suppl. 14:97-104.

10. DU PLESSIS, M. A. 1992. Obligate cavity roosting as a constraint on dispersal of green (red-billed) woodhoopoes: Consequences for philopatry and the likelihood of inbreeding. Oecologia 90:205-211.

11. DU PLESSIS, M. A. and WILLIAMS, J. B. 1994. Communal cavity roosting in green woodhoopoes: Consequences for energy expenditure and the seasonal pattern of mortality. Auk 111:292-299.

12. ELDER, W. H. 1954. The oil gland of birds. Wilson Bull. 66:6-31.

13. FRANCIS, G. W. and VELAND, K. 1981. Alkylthiolation for determination of double-bond positions in linear alkenes. J. Chromatogr. 219:379-384.

14. HESSE, M.,MEIER, H., and ZEEH, B. 1987. Spektroskopische Methoden in der organischen Chemie. Thieme Verlag, Stuttgart, Germany, p. 102.

15. JACOB, J. 1978. Hydrocarbon and multibranched ester waxes from the uropygial gland secretion of grebes (Podicipediformes). J. Lipid Res. 19:148-153.

16. JACOB, J. and ZISWILER, V. 1982. The uropygial gland, pp. 359-362, in D. S. Farner, J. R. King, and K. C. Parkes (eds.). Avian Biology (VII). Academic Press, London.

17. LIGON, J. D. and LIGON, S. H. 1978. The communal social system of the green woodhoopoe in Kenya. Living Bird 16:159-197.

18. REITER, B., BURGER, B. V., and DRY, J. 2003. Mammalian exocrine secretions. XVIII: Chemical characterization of interdigital secretion of red hartebeest, Alcelaphus buselaphus caama. J. Chem. Ecol. 29:2235-2252.

19. WENKERT, E., BUCKWALTER, B. L., BURFITT, I. R., GASIC, M. J., GOTTLIEB, H. E., HAGAMAN, E. W., SCHELL, F.M., andWOVKULICH, P.M. 1976. Carbon-13 nuclear magnetic resonance spectroscopy of naturally occuring substances, pp. 81-121, in G. C. Levy (ed.). Topics in Carbon-13 NMR Spectroscopy, Vol. 2. Wiley., New York.

20. ZHANG, Z. and PAWLISZYN, J. 1993. Analysis of organic compounds in environmental samples by headspace solid phase micro-extraction. J. High Resolut. Chromatogr. 16:689-692.

21. ZIEGENBEIN, W. 1969. Synthesis of acetylenes and polyacetylenes by substitution reactions, pp. 169-263, in H. G. Viehe (ed.). Chemistry of Acetylenes. Marcel Dekker, New York. 